\title{
Formation of Nanoporous Structures of Polypropylene Irradiated by High Energy Heavy Ions
}

\author{
A.M. Maharramov, M.A. Ramazanov*, F.V. Hajiyeva and S.Q.Aliyeva
}

Baku State University, Baku, Azerbaijan

\begin{abstract}
The present work is devoted to preparation of track membranes by irradiation of polymeric film of isotactic Polypropylene (PP) with accelerated heavy ions of xenon (energy $1.3 \mathrm{MeV} /$ nucl, flow density $10^{8}$ up to $10^{10}$ ion $/ \mathrm{sm}^{2}$ ). The further chemical treatment of irradiated film with $\mathrm{KOH}$ (Potassium Hydroxide) solution leads to formation of pores in the polymeric film. It was found that the optimal conditions of track etching of heavy ions in polymer have been studied by the process of pores etching in polymeric film by Atomic Force Microscopy (AFM) method. It has been found out by AFM method, that increase of Xe ions beam density from $10^{8}$ up to $10^{10}$ ion/sm $\mathrm{sm}^{2}$ leads to increasing of number, diameter and depth of pores on the surface and from within of polypropylene film. The influence of alkali concentration and temperature on size and depth of pores in the polymeric film has been detected. It has been shown that increasing of concentration of alkali $0.25 \mathrm{M}$ up to $1.5 \mathrm{M}$ and temperature up to $80^{\circ} \mathrm{C}$ lead to decreasing of diameter and depth of pores in polypropylene matrix.
\end{abstract}

Keywords: Irradiation; Heavy ions; Atomic-force microscope; Polypropylene; Nanopores

\section{Introduction}

Preparation of nanostructure with given properties and formation of functionalized nanomaterials on its basis is one of the most important area of modern materials. Nanomaterials are perspective materials in terms of their application in storage device with over high density of recording, in laser active elements with altering wave length, in microelectronics and ESC (Embedded System Conference). Unfortunately the met stability of compound in nano crystalline state strongly complicates practical application of nanosystem. This is connected with increasing of specific surface contribution and surplus surface energy of physical chemical properties of system. The diminution of the linear size of particles up to nanosize leads to increasing chemical activity and aggregation of nanoparticles. Therefore widely apply the methods of preparation of nanomaterials on the basis of polymeric matrixes. This method prevents the aggregation of nanoparticles as an external influence and as a sequence facilitates the application of these materials.

There are different physical and chemical methods of modification of polymer properties. The nuclear technology method takes special place among versatile modification methods of polymer properties and preparation of nanostructure materials on its basis. The technology of porous polymer nanostructures preparation is based on an irradiation of various polymers by heavy ions with high energy, which induce narrow latent tracks for the whole thickness of a polymeric material. It is known that charged particle moving with high velocity through polymer film forms radiation damage canal (hidden, latent tracks) with identical defect density. Latent tracks represent a defective zone with diameter $\sim 5-12 \mathrm{~nm}$. Following selective etching removes this defective zone and form porous material with nanopores having within limits density $\left(10^{6}-10^{9}\right) \mathrm{sm}^{-2}$. It is possible to receive the structures having specified geometrical parameters by controlling the spatial distribution of the particles forming tracks and etching conditions.

At the present time there are continuing researches in the field of physical and chemical modification of surface and porous structure of polymer materials with the aim of improving its operational characteristics and preparation of membranes with given properties.
It is supposed that nanomodification of polypropylene matrix by accelerated beam of heavy ions leads to preparation of new polymeric structures with nanosized pores and controlled physical, chemical and mechanical properties [1].

The purpose of present work is the evaluation by Atomic Force Microscopy (AFM) method of influence of different factors such as: flow of heavy ions, temperature and concentration parameters of etching on sizes and depth pores of polypropylene track membrane.

\section{Methods of Experiments}

Polypropylene (PP) film samples with thickness 100 micron have been prepared by hot pressing method from isotactic polypropylene powder with particles size 0.5-1.0 micron. Then the film samples were irradiated by high energy heavy ions with further chemical treatment.

The PP film samples were irradiated by Xe ion beam with energy $1.3 \mathrm{MeV}$ at flow from $10^{8}$ up to $10^{10} \mathrm{ion} / \mathrm{sm}^{2}$ on cyclotron AC-100 in the laboratory of nuclear reaction JINR. Uniform irradiation of all parts of film by heavy ions is carried out by beam reamer in horizontal plane by alternating electric field scanning with frequency $2000 \mathrm{~Hz}$. The velocity of film moving in irradiation process is within 0.1 up to $2 \mathrm{~m} / \mathrm{sec}$ depending on ion beam intensity and density. Irradiation was carried in special vacuum chamber with tape mechanism. Accelerated beam of xenon ions was taken out from chamber by means of electrostatic deflector and was directed to chamber for a film irradiation. The xenon beam enters in vacuum chamber for irradiation of film after passing through scanning system $[2,3]$. Irradiation films were treated by $0.5 \mathrm{M}$ and $1.5 \mathrm{M}$ aqueous solution of $\mathrm{KOH}$ at $80^{\circ} \mathrm{C}$ for one hour. Investigation

*Corresponding author: M.A. Ramazanov, AZ 1148, Zahid Khalilov Str.23, Baku State University, Baku, Azerbaijan, E-mail: mamed_r50@mail.ru, nanomaterials@bsu.az

Received March 27, 2012; Accepted June 07, 2012; Published June 12, 2012

Citation: Maharramov AM, Ramazanov MA, Hajiyeva FV, Aliyeva SQ (2012) Formation of Nanoporous Structures of Polypropylene Irradiated by High Energy Heavy lons. J Nanomed Nanotechol 3:141. doi:10.4172/2157-7439.1000141

Copyright: (c) 2012 Maharramov AM, et al. This is an open-access article distributed under the terms of the Creative Commons Attribution License, which permits unrestricted use, distribution, and reproduction in any medium, provided the original author and source are credited. 
of dependence of etching velocity of through track on temperature, concentration and etching duration allow choosing the optimal regime of etching, giving through track.

\section{Results and Discussion}

Passing through irradiated film, heavy ion forms channel of strong radiation damage. At the formed channels the molecules of irradiated polymer are distrupted and splited into fine components (radicals). The heavy ion loses the part or whole energy by interaction with irradiated compound. At the same time it makes radiation damage of compound along a track. As a result it forms the area with modified structure, that has high solubility. The irradiation of polymers by heavy ions leads to chemical bond changes due to disruption or cross sewing of molecular chains. The disruption leads to forming of short chain molecules with high radiation resistance. The sequence of disruption is the change of compound properties in a latent track: decreasing of molecular weight, increasing of polymer solubility, reduction of softening temperature, deterioration of mechanical properties. Radicals, ions and activated molecules, forming at polymer irradiation, excite the polymer molecules interaction. As a result of these interactions the bonding of macromolecules by carbon bridges and formation of branched spatial net take place.

However, the sensibility of polymers to slight changes of chemical structure is too high and the changing of even chemical bond leads to modification of polymer. As a result we got a modified polymer with different solubility, viscosity and durability. The further action of specially selected chemical etching on irradiated polymer leads to forming of hollow etching channels.

The changes of topography and physical structure of polypropylene induced by irradiation with accelerated heavy ions have been studied by AFM method. There are images of films surface of polypropylene irradiated by Xe accelerated heavy ions with energy $1.3 \mathrm{MeV}$ at torrent $10^{8}-10^{10} \mathrm{ion} / \mathrm{sm}^{2}$. The microscopic images show that formed pores on the first stage of etching "close" due to swelling of etched polymer. AFM studies demonstrate that etching process begins from local swelling of polymer in track area, and it leads to formation of so-called protuberances (Figure 1). The appearance of protuberances evidently connected with extraction (pressing out) of destructive polymer from damage area.

The protuberances size at etching in alkali is approximately same of size as damaged track area. It is known that etching process consist of several stages [4-7]. The first stage of etching starts with extraction of the radiolysis products through the track from its core and ended by formation of primary through channels. The second stage starts with the polymer swelling in track area and formation of characteristic zones filled by gel; this stage completes by closing primary through channels. The time of track swelling defines the average velocity of etching. On the third stage the gel partially passes in etcher solution; at the same time minimum sized pores form on tracks (for example, for Xe ion with energy $1 \mathrm{MeV} /$ a.u. in PP the average diameter of holes makes is 20-140 nm). Then the further etching of changed area of polymer takes place, i.e. the further swelling of pores walls and passing of formed gellayer to etcher solution. And only after completion of passing of gel from the changed track area (for Xe ion the changed area is up to 60 nM) starts radial etching of pore walls TM (Track Membrane) up to demanded diameter.

It is shown that thermal treatment and etching change the structure of track in polymers. In Figure 2 there are AFM images of

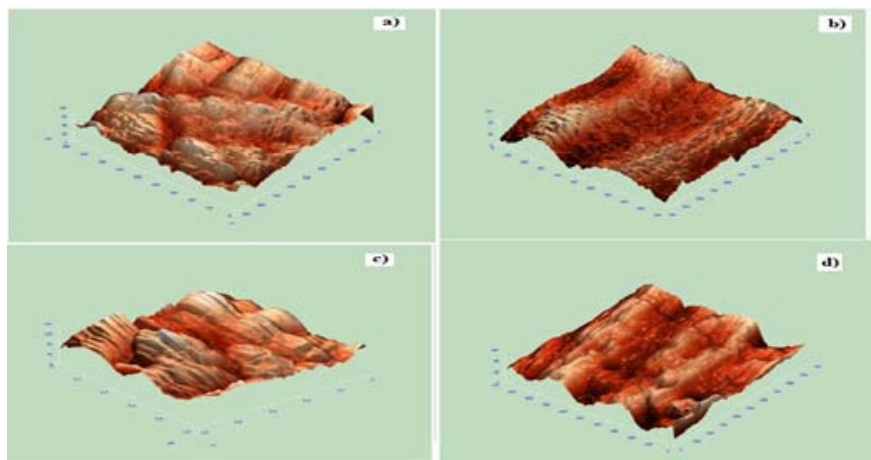

Figure 1: AFM images of polypropylene irradiated by $\mathrm{Xe}$ accelerated heavy ions with energy $1.3 \mathrm{MeV}$. a) non-irradiated film of PP, b) films of polypropylene irradiated by Xe ions at flow $10^{8} \mathrm{ion} / \mathrm{cm}^{2}$, c) films of polypropylene irradiated by Xe ions at flow $10^{9} \mathrm{ion} / \mathrm{cm}^{2}$, d) films of polypropylene irradiated by Xe ions at flow $10^{10} \mathrm{ion} / \mathrm{cm}^{2}$.

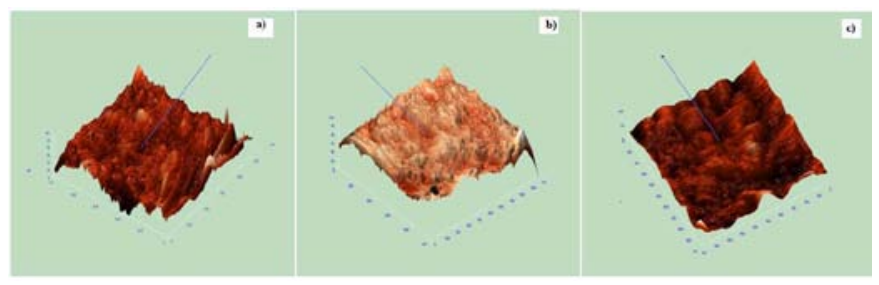

Figure 2: AFM images of polypropylene samples irradiated by $\mathrm{Xe}$ ions with energy $1.3 \mathrm{MeV}$ and etched by $0.25 \mathrm{M}$ solution of $\mathrm{KOH}$. a) films of polypropylene irradiated by Xe ions at flow $10^{8} \mathrm{ion} / \mathrm{cm}^{2}$ b) films of polypropylene irradiated by $\mathrm{Xe}$ ions at flow $10^{9} \mathrm{ion} / \mathrm{cm}^{2} \mathrm{c}$ ) films of polypropylene irradiated by Xe ions at flow $10^{10} \mathrm{ion} / \mathrm{cm}^{2}$.

polypropylene samples etched by $0.25 \mathrm{M}$ solution of $\mathrm{KOH}$.

As it is shown in the Table 1 with increasing flow of ions the amount, diameter and depth of pores on surface and volume of polypropylene films also increase.

Also experimentally found that the increasing of $\mathrm{KOH}$ solution concentration leads to changes of pores diameter and depth in polypropylene matrix. So, in case with $1.5 \mathrm{M}$ solution of $\mathrm{KOH}$ pores diameter and depth decrease in contrast to $0.25 \mathrm{M}$ of $\mathrm{KOH}$ (Table 2).

Preparation of track membranes with enhanced properties reached in case with high temperature chemical etching. However, the carrying out the process at over $100^{\circ} \mathrm{C}$ leads to dramatical decline of the selectivity of process, and as consequence to deterioration of structural characteristics of membranes. The carried out researches confirms that thermal treatment of polypropylene film at etching process in alkali define the depth and size of pores. In Figure 3 and Figure 4 the results of AFM studies of polypropylene irradiated track membranes, etched in alkali solution at $80^{\circ} \mathrm{C}$ were presented.

It is shown that increasing the temperature up to $80^{\circ} \mathrm{C}$ leads to decreasing of diameter and depth of pores in polypropylene (Table 3 ).

\section{Conclusion}

The main idea of the present work using the techniques of nuclear technology and creating tracks in polymer matrices to obtain the quantum wire, i.e, the nanostructure microns in length throughout the thickness of the polymer material. Application of atomic force microscopy method allows taking into account the shape of pores, channels and the topography of the surface irradiated polymer films. 
Citation: Maharramov AM, Ramazanov MA, Hajiyeva FV, Aliyeva SQ (2012) Formation of Nanoporous Structures of Polypropylene Irradiated by High Energy Heavy lons. J Nanomed Nanotechol 3:141. doi:10.4172/2157-7439.1000141

Page 3 of 3

\begin{tabular}{|c|c|c|c|}
\hline Flow (ion/sm²) & $10^{8}$ & $10^{9}$ & $10^{10}$ \\
\hline Diameter of pores in PP matrix $(\mathrm{nm})$ & $20-70$ & $30-80$ & $60-140$ \\
\hline Depth of pores (nm) & $3-5$ & $5-10$ & $20-30$ \\
\hline
\end{tabular}

Table 1:

\begin{tabular}{|l|c|c|}
\hline Concentration of $\mathrm{KOH}(\mathrm{mol} / \mathrm{l})$ Temperature $\left(\mathbf{2 0 ^ { \circ }} \mathrm{C}\right)$ & $\mathbf{0 . 2 5}$ & $\mathbf{1 . 5}$ \\
\hline Diameter of pores in PP matrix (nм) & $60-140$ & $50-100$ \\
\hline Depth of pores (nм) & $20-30$ & $7-25$ \\
\hline
\end{tabular}

Table 2:

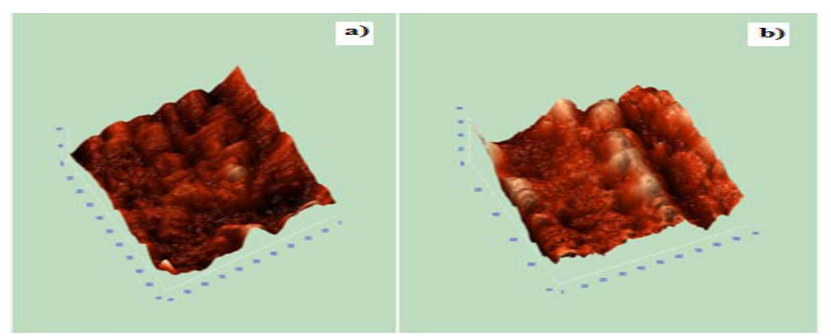

Figure 3: AFM images of polypropylene irradiated by Xe ions with energy 1.3 $\mathrm{MeV}$ at flow $10^{10} \mathrm{ion} / \mathrm{cm}^{2}$ and etched in an aqueous solution of $\mathrm{KOH}$ : a) PP etched in $0.25 \mathrm{M} \mathrm{KOH}$, b) $\mathrm{PP}$, etched in $1.5 \mathrm{M} \mathrm{KOH}$.

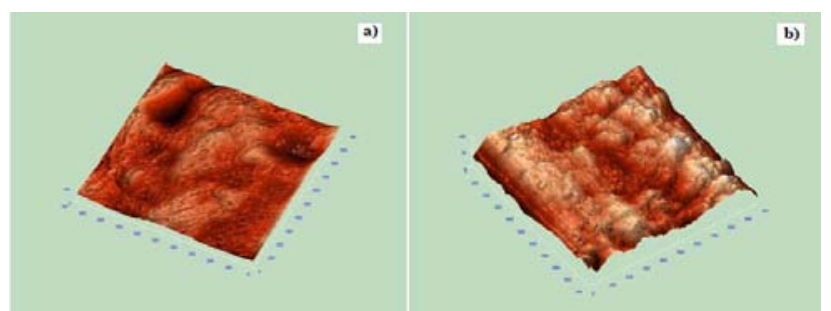

Figure 4: AFM 3D images of polypropylene irradiated by Xe ions with energy 1.3 MeV at flow $10^{10} \mathrm{ion} / \mathrm{cm}^{2}$ and etched in an aqueous solution of $\mathrm{KOH}$ at $80^{\circ} \mathrm{C}$.

\begin{tabular}{|l|c|c|}
\hline Concentration of $\mathrm{KOH}(\mathrm{mol} / \mathrm{l})$ Temperature $\mathbf{( 8 0 ^ { \circ } \mathrm { C } )}$ & $\mathbf{0 . 2 5}$ & $\mathbf{1 . 5}$ \\
\hline Diameter of pores in PP matrix (nм) & $30-100$ & $40-90$ \\
\hline Depth of pores (nM) & $3-20$ & $3-12$ \\
\hline
\end{tabular}

Table 3:

It has been shown that thermal treatment and etching reveal the real structure of track in polymer. Varying the conditions of ionic radiation (type and energy of ion, application of multi component bundles) it is possible to manage with nano extraction (average size, orientation, crystalline).

\section{Acknowledgements}

The authors is thankful to Join Institute for Nuclear Research, Dubna, Russia and especially, to P.Tu.Apel for providing irradiation facility.

\section{References}

1. Reutov VF,Dmitriev SN (2002) Ion track nanotechnology. Russian Chemical Journal 46: 74-80.

2. Flerov QN, Apel PJ, Didyk AJ, Kuznetsov VI, Oganesyan RS (1989) Atomic energy 67: 274.

3. Golovkov VM, Sohoreva VV (2009) lonic-track nanotechnologies of reception of membranes and nanostructures. Russian Physics Journal 52: 413.

4. Vilenskey Al, Olejnikov VA, Poppies HT, Mchedlivili BV, Dontsova EP (1994) Polyimide track membranes for ultra-and microfiltration. Polymer Science 36: 475 .

5. Apel P Ju, Berezkin VV, Vasilev AB, Vilensky AI, Mchedlishvili BV (1992) Structure-selective properties of nuclear filters based on polypropylene. Colloidal Journal 54: 220

6. Vilenskey Al, Tyolstihina AL(1996) News of academy of Sciences. Chemistry series 6: 1115 .

7. Vilenskey AI, Zagorski DL, Bystrove SA, Michailovab SS,Gainutdinova RV, et al. (2002) Investigation of latent tracks in polyethyleneterephthalate and their etching, Surface Science 507: 911-915. 